\title{
La demanda moral hacia los políticos
}

\section{Moral demand on politicians}

\author{
Héctor Gutiérrez Sánchez
}

DOI: https://doi.org//0.32870/

eees.v26i76.7097

\section{Resumen}

Este artículo explora la reciente hipótesis de la existencia de una demanda moral hacia los políticos en México. Se parte de estudios y estadísticas en torno al descontento social al respecto, y se anticipa cómo la moral es valiosa pero vulnerable, y que su trasgresión genera animadversión. Metodológicamente, el trabajo se apoya en la teoría durkhemiana, entrevistas y una encuesta. Se concluye que como los gobernantes son figuras públicas y electas, se constituyen en objeto de intenso escrutinio moral, más allá de sus funciones oficiales dictadas por ley.

Palabras clave: desencanto político, opinión pública, percepción ciudadana, moral, partidos.

\begin{abstract}
This article explores the recent hypothesis of a moral demand on Mexican politicians. Studies and statistics are used as a basis to show social political disenchantment, and we anticipate how morality is valuable but vulnerable, and how any transgression generates animosity. Durkheim's theory, interviews and a survey integrate methodology. We concluded that as political figures are public and elected, they are subjects of intense moral scrutiny beyond their official and legal functions.
\end{abstract}

Keywords: Political disenchantment, public opinion, citizen's perception, moral, parties.

\footnotetext{
- Profesor-Investigador de la Facultad de Ciencias Políticas y Sociales de la Universidad Autónoma de Querétaro, México. ORCID: https://orcid.org/0000-0002-2646-7I9X

ciudadanohector@yahoo.com.mx

Fecha de recepción: 30 de marzo de 2019. Fecha de aceptación: 08 de junio de 2019.
} 


\section{Introducción}

Este artículo revisa con mayor detalle empírico y teórico una hipótesis que se ha propuesto anteriormente, según la cual la ciudadanía mexicana tiene expectativas morales sobre sus gobernantes (Gutiérrez, 2018). Se ha señalado que esta demanda no está satisfecha, y que podría ser una importante causa del desencanto político nacional. El objetivo del presente texto es describir de mejor manera dicha demanda. Para ello, primero se detalla el contexto general de los estudios sobre desencanto y opinión pública, se presenta el planteamiento del problema y se muestra la relevancia de la idea, su origen y su pertinencia científica.

El resto del trabajo se organiza en tres secciones. La primera es cualitativa y presenta los resultados de una serie de entrevistas semiestructuradas hechas para obtener una primera imagen inductiva del fenómeno. La segunda recupera la primera imagen inductiva y la aclara a la luz de teoría política y sociológica. En la tercera, se atiende la dimensión del fenómeno estudiado, dado que esta demanda moral podría ser un fenómeno limitado o generalizado, lo que cambiaría mucho su relevancia. Al final, se presentan las conclusiones.

\section{Entendiendo el descontento político}

Contrario a otros momentos de su historia, actualmente México posee un sistema político caracterizado por la competencia: diversos grupos con diferentes agendas e intereses luchan por acceder al poder político, y para lograrlo necesitan la legitimidad y el beneplácito de la población, ya sea esto proveniente de las urnas o no.

Esto se ve con claridad en el constante esfuerzo que ponen los Gobiernos para legitimarse y ganar el favor ciudadano, y en el constante intento de la oposición por desacreditar a

\section{4}


sus rivales en el poder. Ya que el destino del país depende -en mayor o menor medida- de la voluntad popular, esta es un elemento relevante para comprender el sistema político de este país.

Sin embargo, la opinión pública importa no sólo porque determina qué grupos acceden al poder y cuál es su margen de maniobra política, sino también porque podría ser un obstáculo para la democratización del país. Durante las últimas décadas, se ha pensado recurrentemente que los mexicanos están políticamente inconformes (García, 2004; Cuna, 2006).

Si bien antes de la alternancia de partido gobernante sucedida en el año 2000 a nivel federal se creía que eso era bueno, pues se pensaba que el descontento era producto de una población que se hacía cada vez más democrático-participativa -lo cual chocaba con las estructuras del partido hegemónico (Alonso, 1994)-, la misma alternancia parece haber alterado el rol del desencanto político. En las elecciones de 2003, autores como Mora y Rodríguez (2003) notaron una baja en la participación electoral y sugirieron que los pobres resultados del nuevo Gobierno en sus primeros tres años de actividad eran los responsables.

En la literatura, hay algo de desacuerdo en torno a cómo y en qué medida el desencanto político se relaciona con conductas antidemocráticas, pero generalmente se reconoce que el desencanto se vincula con el abstencionismo, el voto nulo y otras anomalías en la participación (Alonso, 2010).

A esto habría que agregarle un trabajo de Zovatto (2006) donde se sugiere que una baja participación electoral puede ser problemática para una democracia en vías de consolidación, pues podría desilusionar a los grupos que buscan mayor democracia y evitar con ello la consolidación. Incluso, se plantea que la baja participación electoral podría dar paso a regresiones autoritarias (Torcal, 2003), todo esto además de que en las democracias más consolidadas no parece haber 
una relación entre desencanto y abstención, cosa que sí se percibe en democracias más jóvenes e incipientes.

Así, la opinión ciudadana es relevante porque marca los rumbos políticos nacionales a través del voto y otras formas de participación. Además, actualmente dicha opinión es negativa, y eso parece ser un problema para lograr una consolidación democrática.

Establecida la relevancia del tema, se plantea como pregunta de trabajo ¿por qué los mexicanos parecen políticamente insatisfechos? Quizá la popularidad del presidente mexicano es de momento alta (Consulta Mitofsky, 2019), pero claramente la población tiene una mala imagen de sus instituciones públicas y de muchas figuras como diputados, gobernadores, jefes de partido, presidentes municipales y otros. ¿En qué consiste y qué determina el juicio de dicha sociedad civil?

La respuesta más común y aparentemente obvia es que la opinión pública reacciona a cómo los Gobiernos y actores políticos llevan la administración pública:

El Estado y sus instituciones requieren, pues, de la legitimidad que les aportan los individuos, $y$ al Gobierno los ciudadanos. Esta legitimidad se fundamenta por el desempeño gubernamental para alcanzar los objetivos de Estado propuestos (aquí la clave es la eficacia). (García, 2004, p. 175)

[...] tienen culpa los políticos y las instituciones, que agravaron las dificultades con su pobre desempeño. (Cuna, 2006, p. 99)

Hablar de desempeño resulta vago pues el Gobierno tiene muchas funciones. No obstante, se suele coincidir con Lijphart (1999) en que la economía (combate a la pobreza y el desempleo, principalmente) y la seguridad (manejo de la violencia) son los temas más relevantes vinculados a sus funciones: "Esta evaluación se explica por la expectativa de los ciudadanos en tres elementos de su vida práctica: cómo 
la política ayuda en el combate a la pobreza, a la generación de empleo y al mantenimiento de la seguridad pública" (Cuna, 2012, p. 115).

Aunque parece plausible que la razón por la que los mexicanos están molestos con el Gobierno es su pobre desempeño, esta hipótesis parece ser falsa. Un estudio reciente (Gutiérrez, 2018) encontró que sí hay una relación entre la evaluación del Gobierno y la percepción de seguridad y economía, pero que esta relación no se presenta al cambiar la percepción de economía/seguridad por datos reales sobre estas, es decir, quienes ven peor la economía sí evalúan peor al Gobierno, pero los estados más prósperos o seguros no presentan mejores evaluaciones del Gobierno.

Además, el citado estudio hizo una revisión longitudinal y descubrió que el desempleo, la pobreza, las tasas de homicidio y el crecimiento del producto interno bruto (PIB) fluctuaban mucho a lo largo de los años, mientras que el descontento con el Gobierno se mantenía estable, es decir, los años en que la economía y la seguridad mejoraban no se correlacionaban con una mejora en la evaluación del Gobierno, ni viceversa. Además, el trabajo encontró que las zonas más ricas o seguras no tenían informantes que creían estar mejor en economía o seguridad, lo que sugiere que las personas no tienen la capacidad de saber si el Gobierno está haciendo bien su trabajo.

Sin duda, los mexicanos están políticamente descontentos, pero no parece que ello se deba a un mal desempeño pragmático de los Gobiernos. Una segunda opción es que estén molestos con la democracia en general. Sobre esta opción, hay múltiples estudios bastante elaborados que siguen con mucho cuidado el pulso de cuánto se apoya la democracia en México y Latinoamérica (Cuna, 2012; Schedler y Sarsfield, 2009; Zovatto, 2002). Sin embargo, los mexicanos son demócratas insatisfechos (Cuna, 2012), es decir, apoyan a la democracia y su malestar está dirigido a 
sus gobernantes y Gobiernos en particular, lo cual se explica por el hecho de que parecen tener una buena opinión hacia la democracia pero no creen vivir en una, pues asumen que esta conlleva una serie de derechos y beneficios que no poseen aunque desean.

Si la molestia ciudadana no parece explicarse por el desempeño pragmático del Gobierno ni ser resultado de una inconformidad respecto a la democracia, otra opción es que el malestar esté apuntado contra los partidos políticos.

El tema de los partidos tiene una larga historia en la ciencia política mexicana, particularmente en relación al llamado modelo Michigan (Campbell, Converse, Miller, y Stokes, 1960). Varios estudios han encontrado importantes relaciones entre el sentido del voto y la identificación partidista (Moreno, 1999), con correlaciones de hasta .87 (Guardado, 2009). Los defensores del mencionado modelo han mostrado que la identificación partidista podría incluso determinar la evaluación que la gente hace de sus Gobiernos y gobernantes (Moreno, 2009), pero esta también es una explicación defectuosa para el desencanto generalizado.

En primer lugar, es sabido que el apego partidista ha estado decreciendo en los últimos años, al punto que los defensores de esta teoría han tenido que justificarse hablando de relevo generacional o de identificaciones partidistas que están temporalmente en transición a otros partidos (Moreno y Méndez, 2007). En segundo lugar, como ya se mencionó, el desencanto parece muy estable en el tiempo.

En tercer lugar, dos trabajos (Gutiérrez, 2017 y 2018) coinciden en señalar que los ciudadanos no ponen su atención en instituciones, sino en personas, es decir, no hay molestia contra algún tribunal o partido, sino contra el gobernante en particular (presidentes de la república, gobernadores y presidentes municipales), lo cual tampoco significa que los partidos sean irrelevantes sino que parecen afectar el juicio ciudadano en la medida en que proyectan

\section{8}


ciertos prejuicios sobre los funcionarios -que son el verdadero objeto de la opinión pública-. En este sentido, es interesante que un partido muy joven y particularmente focalizado en una persona, el Movimiento de Regeneración Nacional (Morena), haya ganado la elección federal en 2018 por sobre los partidos nacionales consolidados.

Como ya se aprecia, aunque decir que la ciudadanía está molesta se ha vuelto casi un lugar común tanto en la academia como en los medios de comunicación, realmente no se sabe por qué los mexicanos están inconformes: no parece ser un tema de resultados pragmáticos del Gobierno, tampoco de desafección por la democracia o por los partidos. Este hueco teórico es inaceptable y justifica la existencia de trabajos como el presente, pero también es una invitación a expandir y explorar nuevos terrenos teóricos, pues si las teorías clásicas y comunes no están dando buenos resultados, habrá que buscar más allá para encontrar respuestas.

En ese espíritu, los dos estudios antes mencionados (Gutiérrez, 2017 y 2018) sugirieron la posibilidad de que el ciudadano tenga una expectativa moral sobre sus gobernantes, es decir, que no sólo busca funcionarios eficientes y efectivos, sino que también quiere gobernantes que sean ejemplos morales y líderes que inspiren a una mejoría en el ejercicio civil. Los estudios han propuesto además que esta demanda no está siendo atendida, y que podría ser una importante causa del desencanto político.

La demanda moral hacia los políticos ha sido abordada previamente por algunos de los trabajos aquí enlistados, pero no a profundidad. El presente trabajo aspira a ahondar en la comprensión de dicha demanda.

\section{Analizar la demanda moral cualitativa-inductivamente}

Aunque mostrar primero las entrevistas y luego la parte teórica haría parecer que el presente trabajo siguió este 
orden en su desarrollo, esto es falso. Realmente, el trabajo se ha desarrollado siguiendo un espiral dialéctico en que se hacían entrevistas, se revisaba la teoría y se volvía a campo para regresar después a los teóricos. El orden actual en el texto está pensado para facilitar la lectura del artículo, no para reflejar el proceso de investigación.

Aclarado esto, la parte cualitativa se basa en cuarenta y nueve entrevistas realizadas en el contexto de dos elecciones: treinta se realizaron en Puebla, entre el 27 y 29 de junio de 2016, unos días antes de su elección de gobernador; seis se hicieron a estudiantes en la Ciudad Universitaria de la Benemérita Universidad Autónoma de Puebla (BUAP); y el resto se aplicaron en el primer cuadro de la misma ciudad a personas que ahí se encontraban. Hubo menos de cinco rechazos (principalmente debidos a haber abordado a las personas en momentos inconvenientes), y se consiguió permiso para grabar trece entrevistas, de las cuales surgen algunos de los fragmentos presentados y analizados más adelante.

Otras entrevistas sucedieron en Querétaro, entre febrero y septiembre, en el contexto de la elección presidencial de 2018; nueve de ellas se aplicaron a población adulta y económicamente activa que atendía cursos en un centro cultural, y el resto se hicieron a estudiantes de la Universidad Autónoma de Querétaro. Se especifica que los informantes son alumnos universitarios porque la encuesta (más adelante se muestra) fue aplicada a esa población, aunque vale la pena señalar que en todo el trabajo se evitaron las instalaciones de las facultades de Ciencias Políticas y Sociales, rehuyendo en lo posible sesgos. Todas las entrevistas queretanas fueron grabadas, y aportan fragmentos que se revisan más adelante.

Las entrevistas fueron semiestructuradas. Con ellas, se intentaba comprender cómo las personas veían y juzgaban a candidatos políticos y gobernantes en funciones. Aprovechando la técnica, se dio gran libertad al entrevistado para 
que hablara, pero se le encaminó sutilmente hacia el interés del estudio, todo esto con el fin de comprender la manera en que cada uno ve y entiende el mundo.

Al preguntarles a las personas cómo juzgan a los políticos, el elemento pragmático surgía muy rápidamente: ${ }^{1}$

¿Cómo decides un candidato sobre otro?, ¿en qué te fijas?

-Básicamente en su trabajo previo.

-En lo que... Qué hayan estudiado.Yo siento que eso es un filtro, por ejemplo, [el candidato del Partido Revolucionario Institucional a la Presidencia de la República, José Antonio] Meade, me sorprende que tenga dos carreras.

Y ¿en qué te fijas de las administraciones pasadas?

-En qué tipo de obras han hecho, escuelas, pavimentar, todas esas cosas.

Este surgimiento de lo pragmático en las entrevistas se antoja comprensible, pero, como se dijo antes, las personas no parecen tener las bases para juzgar el desempeño de los Gobiernos ni parece que este sea el principal aspecto con el que juzgan.

Al profundizar en el tema, los informantes describían otro tipo de características que no parecían tan directamente vinculadas con la eficacia de los funcionarios. Así, la gente decía querer gobernantes buenos "como persona", que "conecten", que "inspiren"; en particular, se buscaba que fueran "humanos", atributo que los informantes deseaban mucho, aunque no lograran definirlo o justificarlo claramente:

I.Se incluyen las preguntas en letras itálicas (cursivas) y las respuestas seleccionadas en tipografía redonda. Cada guion corto (-) indica la respuesta o fragmento de respuesta de un entrevistado distinto. Las grabaciones completas de las entrevistas realizadas están en poder del autor del artículo. 
Y ¿a qué te refieres con "persona"?

-Saber si no es una, si es una persona que es, si es humana, si no es una persona que haya estado involucrada en actos delictivos.

¿A qué te refieres con que son "humanos"?

-Pues que no tienen una persona... Bueno, no, humanos es [sic] todos, ¿no? Nosotros [somos] seres humanos, como humanitario.

-¡Ay! O sea, por ejemplo, ¡ay, no sé! Como de que llegue a un lugar y la gente diga:“¡Ah, no inventes, que buena onda!”, y se pueda acercar y te sientas identificado [con él o ella] por lo que sea.

-A lo mejor, por lo que quieras, a lo mejor por mis creencias o por mi educación o lo que quieras, sí me fijo un poco en eso, que a lo mejor es tonto, ¿verdad? Lo que tú digas.

Por otro lado, los entrevistados no tuvieron problemas cuando describían su deseo de tener un presidente efectivo, bien preparado y con experiencia en el servicio público, pero sí les costó mucho trabajo clarificar su deseo de que también fuera bueno. Además, les resultó difícil aclarar si creían que sus dos deseos estaban relacionados:

-¡Ah!, como actuar, entonces es como, por ejemplo, una persona, como dices, si una... Si ese candidato le pega a sus hijos, entonces itú crees que sea justo con alguna situación? O sea, si no respeta a sus hijos, ¿qué esperas [que haga] con las demás personas?

-Pues claro, pues es que no puede ser, pues es que dime cómo... Si es una mala persona ¿cómo te va a poder brindar justicia, equidad?

Entonces, algunos entrevistados asumían que quien fuera una mala persona en su vida privada no podría ser un buen gobernante, lo que llegaba a generar disonancia cognitiva: ${ }^{2}$

2. El término disonancia cognitiva refiere a una situación en que dos ideas, creencias o emociones contradictorias son experimentadas al mismo tiempo por el mismo

\section{2}


Si tú tuvieras un presidente que lleve la economía súper bien, y la seguridad y todo, pero resulta que es una mala persona, ¿cómo te sentirías?

-Pues engañada, ¿cómo alguien así, que lleva tan bien el país, es malo?

Este hallazgo es destacable, pues las leyes asignan muchas funciones a los cargos ejecutivos pero no especifican que la persona que ocupe el cargo deba ser moralmente ejemplar en su vida privada, la cual se asume ajena a sus funciones públicas. Bajo una lógica estrictamente racional, las personas no deberían interesarse por la calidad moral privada de sus funcionarios. Los informantes del presente estudio, sin embargo, mostraron un claro interés por vincular ambos asuntos.

Dicha compleja relación entre el deseo pragmático de tener funcionarios eficientes y el complicado impulso de querer buenas personas se reflejó particularmente en el tema de la corrupción: los entrevistados generalmente condenaban, de inicio, la corrupción al considerarla un desperdicio de recursos, pero luego, al profundizar en sus respuestas, manifestaban una preocupación distinta a sólo la pérdida del erario:

Si yo te demostrara que la corrupción no afecta porque es una cosa demasiado pequeña, ¿ya no te preocuparía?

-No, claro que sí.

¿La corrupción sólo es mala por afectar la economía?

-O sea, es que no puede ser estrictamente en su papel en la economía, ¿no? Porque conlleva a [sic] más cosas.

sujeto, generando así cierta confusión y tensión en que la persona no logra empatar las partes contradictorias en un marco lógico y coherente. 
Imagínese que hay un programa para pobreza, y eso va a llegar a los pobres. $\mathrm{Si}$ por alguna razón logística, sin que haya una mala intención, un accidente, por un error o lo que sea, se desperdician determinada cantidad de miles o millones de pesos, en su punto de vista, ¿esto es igual a que si un político se lo roba?

-No.

¿Cuál es la diferencia? Porque los pobres igualmente no recibieron el apoyo.

-La diferencia es que se perdió por un accidente, y [en] la otra porque se lo robaron. Esa es la diferencia, la parte ética.

Sobre esto mismo, destaca que los entrevistados parecían dispuestos a disculpar incompetencias honestas, pero no actos de mala fe, independientemente de la escala del daño:

-Si soy honesto, pues voy a ser honesto con las personas que [tengo] alrededor, es decir, te voy a decir:"lo gasté en tal, tal y tal, y no se hizo esto, pero bueno, se podría empezar con...", y yo creo que ese es mi punto: necesitas esos valores, ser congruente, ser honesto.

En un intento por clarificar la demanda moral, se preguntó a los entrevistados sobre qué otra figura recaería. Se encontró que las personas parecen menos interesadas en la calidad personal de quienes tienen oficios manuales o poco visibles, como hacer fotocopias o reparar autos; en el otro extremo, se exigiría calidad moral de figuras más visibles y con posiciones de poder, como sacerdotes y profesores:

Cuando tú contratas a alguien para imprimir tu tesis, ¿te preocupan sus valores?

-Pues ya sería... no, porque lo que me está importando es que me entregue bien mi trabajo, no su vida. 
¿Qué otro oficio o persona o figura esperas que tenga más está capacidad [de inspirar moralmente]?

-Los maestros.

-Tal vez el padre [sacerdote] habla muy bonito, pero a mí tampoco me dice que sea realmente una buena persona, que los valores que dice los está empleando, me está hablando muy bonito, y eso pues está muy bien, es su trabajo y lo que quieras, pero a mí sigue sin demostrarme que es una buena persona.

-Pues porque él que está hablando, está hablando de cosas buenas y hace lo contrario, contrario al otro [el ejemplo del impresor de tesis] que nomás voy por un trabajo y ya, no me está diciendo nada, solamente quiero que esa persona [me] dé las copias, o sea, no me importa su vida, solamente quiero que me entregue bien mi trabajo y ya; si estoy satisfecho, pues está bien, pero a diferencia del padre [sacerdote], que te está diciendo que hay que ser buenos padres, buenos hijos, así, buenas personas, y si él no lo hace, pues entonces no tiene caso, no lo vería nadie como una persona correcta, [lo vería como alguien] que ni [...] siquiera habla con honestidad.

El último fragmento de entrevista reproducido conecta con un punto que fue muy claro en todos los informantes: las personas ven a sus gobernantes como quienes, idealmente, los inspiran a ser mejores, los guían y son un ejemplo para el pueblo:

¿Usted quiere a un presidente que nos guíe?

-Sí. Sí, que sea guía.

-Lo que implica ser un presidente es saber dirigir, es tener dirección, poder dirigir.Yo creo que... supongo que así es como lo veo.

¿Tú crees que lo que haga el presidente se toma como ejemplo para otras personas? 
-Sí.

-Yo siento que debe tener liderazgo, debe de inspirar y debe de inspirar para bien.

-¿Que si [el presidente] debería ser un ejemplo? ¡Claro!

-Ajá, es como un ejemplo a seguir.

-Verlo, no sé, a lo mejor es [verlo como] un poquito de inspiración, ¿no? No que diga “ ¡Wow!”. Si [el presidente] tiene las ganas de hacerlo, es que yo lo voy hacer, es que estoy convencido de que lo vamos a poder lograr. -Pues es que en los políticos [se espera] más ¿no? Se supone que gobiernan y que tienen que hacer las cosas bien y que tienen que ser buenos, $y$ que inspiren a querer hacer algo bien.

Además, los informantes dejaron claro que esa capacidad de liderazgo moral se pierde si el gobernante no es una buena persona y que, nuevamente, esto no está relacionado con su posible eficacia como servidor público:

¿Tú quieres a alguien que los inspire [a los gobernados]?

-Sí.

¿Alguien que te inspire a ti?

-Ajá.

Para eso necesitas que sea buena persona y para eso no cuentan los doctorados, ¿verdad?

- No.

¿[Los gobernantes] tienen que moverte en un sentido emocional o moral?

-Sí.

Ok.Y para poder liderar tienen que tener valores, ¿no? 
-Sí, pues sí.

Si resulta que un candidato es súper infiel con su esposa y le pega, ¿te separa, te aleja de esta empatía?

-Sí, porque va totalmente en contra de mis valores.

Esta misma idea se encontró en negativo, pues los entrevistados quieren a una buena persona en el Gobierno para que los guíe a ser mejores, pero también temen que si se llega a elegir una mala persona esta no generará esa guía y que, además, los valores mismos podrían caer en descrédito:

-Hay que salirnos de esa situación [de elegir gobernantes que son malas personas], no es lo ideal, además, no es ejemplo, si los de arriba dan ese ejemplo, pues ¿qué podemos exigir a los jóvenes [o] niños?

¿Crees que la sociedad se pondría significativamente peor si descubrimos que nuestro presidente, que es súper buen administrador, les pega brutalmente a sus hijos? ¿Crees que empeoraríamos?

-¿Cómo? ¿Que si les pega? Pues es que si el otro señor [el gobernante], el esposo, le pega a su esposa, pues entonces el otro señor [el ciudadano] le va a pegar más [a la suya].

Esta expectativa moral sobre los gobernantes se explica, en parte, porque son figuras muy públicas, y además, como epítome de esto, son electos, de modo que representan al pueblo o, más precisamente, a lo que el pueblo aspira:

-[Lo elegiría] por su imagen, porque creo que podría ayudar a que también la gente se muestre de esa manera, porque es el presidente, toda la gente lo va a estar mirando. 
¿Quisieras un presidente [que fuera] como la mejor versión de los mexicanos?

-Sí.

Bajo estas premisas, fue comprensible que varios entrevistados lamentaran las campañas de guerra sucia entre políticos, pues al manchar la imagen de todos los candidatos frustraban su deseo de ser inspirados por alguno de ellos.

Finalmente, cabe señalar que cuando las personas enlistan los valores o los principios que desean en sus gobernantes hay recurrencia de aspectos como la honestidad, la diligencia y los valores familiares, aunque también se encontró variabilidad, pues algunos informantes se concentraron mucho en la virtud del respeto (sobre todo hacia adultos mayores y personas vulnerables), mientras que otros apreciaban mucho la humildad. La religiosidad también llegó a aparecer como un factor apreciado:

-Porque, por ejemplo, hay cosas de política que implican directamente con las personas, y si no tienes empatía hacia las personas, no, digamos que entra un conflicto.

-Que sean un poco más humildes, que sean más [cercanos] con la gente, que no estén siempre resguardados por los guaruras, que [no] lleguen siempre en autos lujosos, en helicópteros.

-Como [considerar los orígenes] de su familia, qué formación tienen, qué valores tienen, a lo mejor saber [al respecto].

-Para mí, por ejemplo, una cosa que yo creo que es importante, e igual a mucha gente no le parece importante, y más a gente que no es creyente, sería hasta [a] lo mejor [conocer] su religión.

\section{Demanda moral y teoría}

Hasta este punto del trabajo, queda claro que la demanda moral no es precisamente una expectativa racional y consciente, por lo que el discurso directo de los informantes no 
bastaría para describirla. Los discursos de los informantes han hecho un bosquejo de la constitución de dicha demanda moral, pero los mismos mostraron impulsos y contradicciones que no lograron explicar o ampliar satisfactoriamente. Esto hace que sus respuestas al fenómeno sean insuficientes e invita a buscarlas en la teoría.

Para ello, curiosamente, no ha sido la teoría política la que mejor clarifica lo encontrado, sino la sociológica:

El destino social del Gobierno, dice Comte, me parece consistir, sobre todo, en contener de modo suficiente, $y$ en prevenir hasta donde sea posible, esta fatal disposición a la dispersión fundamental de las ideas, de los sentimientos y de los intereses [...] para recordar así, sin cesar, la idea del conjunto y el sentimiento de la solidaridad común. (Durkheim, 2002, p. 377)

Acorde con lo citado, las personas parecen desear que sus gobernantes sean eficientes, pero también quieren que sean moralmente buenos, pues son figuras públicas que los representan y de las cuales esperan liderazgo moral (Figura 1). En el otro extremo, si se elige a personas que carecen de virtudes, se percibe el riesgo de legitimar una conducta indeseada. Cabría preguntarse si dicha creencia se relaciona con las principales corrientes en teoría política. 
Figura 1. Porcentajes de respuesta sobre el papel del presidente de unir y guiar a la nación

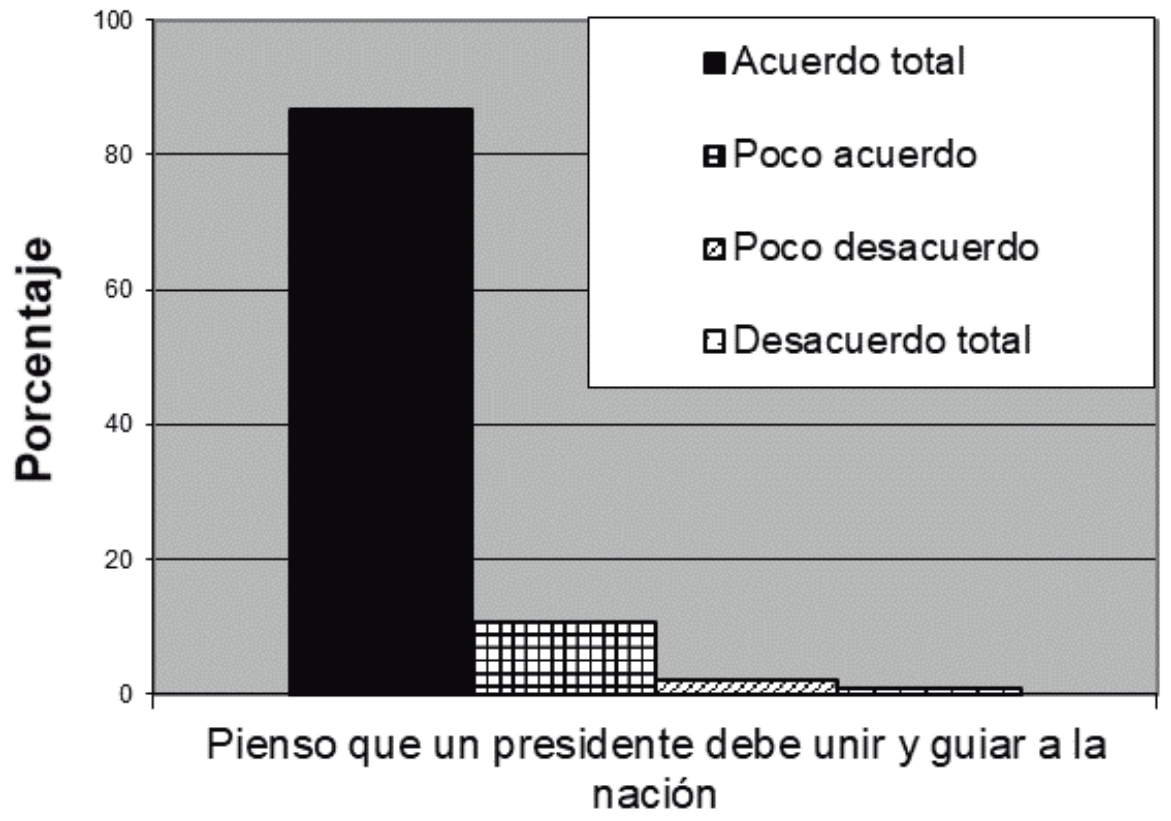

Nota: se hace énfasis en el uso de la palabra nación, y en que no se eligen Estado ni Gobierno.

Fuente: elaboración propia con los datos recabados durante la investigación.

Desde el enfoque psicológico, este hallazgo se relaciona con el concepto de cultura política (Almond y Verba, 1963), categoría que describe lo que las personas saben del sistema político, cómo lo evalúan y cómo se identifican con él. La demanda moral es parte de cómo las personas se vinculan con este, aunque el concepto de cultura politica no aporta mucho a la comprensión de lo aquí presentado, pues en principio fue generado para mostrar cómo la democracia no sólo depende de factores institucionales, sino que también necesita elementos culturales, idea que es interesante pero dice poco sobre por qué la gente espera virtudes morales de sus gobernantes.

\section{0}


La democracia implica valores como la igualdad o la tolerancia a la diversidad, mismos que la ciudadanía podría desear ver en sus políticos, pero el autoritarismo se vincula con otros valores como el nacionalismo, la unidad o la lealtad, valores que igualmente podrían desearse en los gobernantes. Así, pues, la demanda moral no parece relacionarse directamente con la democracia como cultura.

De este modo, la cultura política parece ser tangencial a lo aquí presentado, y algo semejante sucede con el enfoque psicológico en general, pues suponer que los principios rectores de la conducta política se determinan en la crianza temprana, noción propia del enfoque psicológico, dice poco sobre cómo es que las personas adultas desean líderes moralmente intachables.

Algo semejante sucede con el enfoque sociológico, según el cual las ligeras variaciones de los valores demandados se relacionan con grupos sociales. Si esto fuera aplicable al problema de investigación aquí construido, las ciudades con más participación religiosa, por ejemplo, podrían interpretar la fe de los gobernantes como algo bueno e inspirador, lo que probablemente no tendría el mismo efecto en ambientes con alta educación, urbanizados y liberales. La filiación a grupos sociales quizá se vincula con qué se considera bueno e inspirador entre los integrantes de dicho grupo, pero describe poco el mecanismo de preferencia en sí, de modo que el enfoque sociológico tampoco aclara completamente las dudas arrojadas por la parte cualitativa-inductiva de la presente investigación.

Finalmente, es probable que el enfoque racional tenga la relación más extraña con la demanda moral, pues claramente los informantes no son seres conscientes y racionales si esperan virtudes privadas de funcionarios públicos. Esto hace a dicho enfoque desdeñable. Sin embargo, la ciudadanía sí parece estar buscando lo que quiere (por vago o impreciso que sea), pues los informantes decían estar 
dispuestos a votar por la persona que más les ofreciera la inspiración moral que buscaban. Si las personas estuvieran persiguiendo una meta, esto las haría racionales, aunque esta corriente teórica no ayudaría a clarificar dudas e inconsistencias respecto a las propias creencias que surgieron en las entrevistas.

Como se adelantaba, la teoría de Durkheim fue la que mejor dio un contexto coherente a la demanda moral y la que más ayudó a clarificarla. Sin embargo, trabajar con textos clásicos conlleva el problema de que han sido tan discutidos que puede resultar difícil separar el trabajo original de aquello que se suele recuperar sobre él.

Es importante señalar, entonces, que el presente artículo no aspira a hacer una nueva lectura de Durkheim ni a revisar o discutir la gran cantidad de interpretaciones que se han hecho sobre las ideas del autor, empresas que caerían fuera del alcance e intereses de este artículo. Más bien, lo que, en pos de la claridad, se desea señalar es que este trabajo se aleja de la interpretación de Durkheim como el autor de lo externo y coercitivo (Durkheim, 2000) y de varias lecturas de estructuralistas norteamericanos. Lo que aquí se rescata de Durkheim es más próximo a lo recuperado por sus discípulos franceses de filiación antropológica, como Marcel Mauss o Robert Hertz.

Para aquellos que no están familiarizados con la teoría sociológica, vale la pena recordar que casi todo gran sociólogo tiene su propia visión de lo social. A veces, se pone mucha atención en cómo la intención más o menos consciente determina la acción (Weber, 2008), y en otros casos se proponen actores interesados que al seguir sus metas generan un entramado de relaciones recíprocas (Elias, 2008).

La visión durkhemiana resulta útil aquí no sólo por su énfasis en lo moral, sino también porque tiene tres elementos que son de gran valor para este trabajo: primero, entiende lo social como algo benigno para el individuo;

\section{2}


segundo, lo ve como algo vulnerable cuya amenaza genera consternación; y finalmente, asume que todo este mecanismo no recae directamente sobre la consciencia de los individuos.

Sobre el primer punto, Durkheim suele ser recordado como un sociólogo de las estructuras externas al sujeto, las cuales lo limitan y se le oponen, aunque una lectura más cuidadosa muestra cómo lo social durkhemiano es muy benigno para el individuo:

La sociedad, esa fuente única de todo lo que es sagrado, no se limita tan sólo a presionarnos desde afuera y a afectarnos de manera pasajera, sino que se organiza en nuestro interior de una manera duradera. Allí provoca todo un mundo de ideas y sentimientos que, al mismo tiempo que la expresan, forman parte integrante y permanente de nosotros mismos. (Durkheim, 200 I, p. 246)

Nuestra consciencia moral es algo así como el núcleo alrededor del que se ha formado la noción de alma; y sin embargo, cuando esta nos habla, nos parece el efecto de una potencia exterior y superior a nosotros, que nos dicta su ley y nos juzga, pero que también nos ayuda y sostiene. Cuando la tenemos a nuestro favor, nos sentimos más fuertes contra los embates de la vida, más seguros de superarlos, del mismo modo que el australiano, confiado en su ancestro $o$ en su tótem personal, se siente más valeroso contra sus enemigos. (Durkheim, 200I, p. 26I)

Para Durkheim, lo social es parte esencial de la persona, y cuando se debilita, el sujeto sufre. Si esta debilidad se generaliza, se llega a la anomia, una situación en que -por alguna razón- la sociedad no logra guiar adecuadamente a las personas, lo que no sólo provoca caos a un nivel comunitario, sino que también perjudica a los sujetos. Una sociedad anómica, cuyos valores son frágiles, es propensa a confrontaciones interiores, y la fragilidad de lo social 
también perjudica a las personas haciéndolas, por ejemplo, susceptibles al suicidio.

La preocupación por mantener y estabilizar el orden social tiene su extremo en la necesidad de evitar la anomia, pero hay también amenazas más cotidianas a esta normatividad moral. Esto es muy conveniente para el presente trabajo, pues las entrevistas realizadas mostraron valores morales relativamente bien establecidos y generalizados, por lo que el estudio no parece estar ante una situación anómica en la sociedad mexicana. La anomia recuerda la benignidad de lo social y la importancia de evitar el caos moral, pero no describe bien el caso en estudio. Afortunadamente, la sociología durkhemiana revisa también situaciones más cotidianas en que lo moral se ve amenazado sin llegar a estados críticos; los dos mejores ejemplos de esto son las presencias habituales del crimen y la muerte.

Durkheim (2002) aprovechó el tema del crimen para plantear su argumento sobre las solidaridades mecánica y orgánica. Según este autor, todo crimen implica una pena, pero esta no es un mecanismo de disuasión para evitar más comportamiento antisocial, sino una reacción violenta de la moral ofendida de las personas, pues todo crimen "ofende los estados fuertes y definidos de la consciencia colectiva" (Durkheim, 2002, p. 90). De ahí que los castigos consisten en

una reacción pasional [...]. La prueba está en que no buscan ni castigar lo justo ni castigar útilmente, sino sólo castigar. Por eso castigan a los animales que han cometido el acto reprobado, e incluso a los seres inanimados que han sido el instrumento pasivo. (Durkheim, 2002, pp. 95-96)

En la visión durkhemiana, cuando algo -como un crimenofende a las consciencias y choca con los valores socialmente aceptados, causa indignación, ira y una reacción visceral en su contra.

\section{4}


Cabe resaltar que esta explicación de la pena no pasa por la consciencia deliberada y racional del individuo. El horror que causa un crimen no es un producto lógico de una consciencia racional: incluso si el crimen amenaza al orden social -lo que es inconveniente para el individuo-, la condena de una transgresión no es producto de una racionalización medios-fines, sino que consiste en una reacción visceral e irracional. Esta visión se opone a la de otros autores como Skinner-Burchus (1977), quien creía que los castigos son mecanismos de condicionamiento social para evitar conductas indeseables.

La visión conductista es más racional, pero no concuerda con la evidencia empírica, pues la sociedad castiga en proporción a qué tan ofendida está (qué tan horrible fue el crimen), no en proporción a cuánto tardaría en suceder un reacondicionamiento, además, la ira colectiva suele destruir también seres inanimados o instrumentos de crimen, y finalmente, la pena capital claramente no es un reacondicionamiento y es poco eficaz como disuasoria de futuros crímenes.

También hay que considerar que la reacción social ante un crimen se explica por la propia vulnerabilidad del grupo: una sociedad con estructuras sociales invulnerables no sólo sería carente de crimen, sino que no tendría una reacción tan violenta ante sus rupturas, pues se sabría segura, invencible.

Otro ejemplo de cómo las estructuras de una sociedad son amenazadas y provocan una reacción poco consciente es la muerte. Durkheim trabajó sólo de manera indirecta con la muerte cuando hizo su estudio sobre religión (2001), pero Hertz (1960) continuó esa línea de trabajo de su maestro y encontró que

la sociedad imprime su propio carácter permanente a los individuos que la componen: porque se siente inmortal y desea serlo, no puede 
normalmente creer que sus miembros, sobre todo aquellos en los que se encarna y con los que se identifica, deban estar condenados a morir. (Hertz, 1960, p. 77)

Según esta perspectiva, los sepelios son rituales con los que la sociedad intenta resarcirse cuando la muerte la hace sentir vulnerada: "la sociedad, perturbada por el golpe, debe gradualmente recuperar su balance" (Hertz, 1960, p. 82). Esto se relaciona con el hecho de que la muerte es más relevante cuando es pública: la muerte de un esclavo o un niño no bautizado causa menos conmoción y provoca menos rituales que la de un jefe tribal o la de un jefe de Estado, más aún si el sistema político se construye alrededor del culto al líder.

$\mathrm{Al}$ igual que el crimen, la muerte da cuenta de cómo la sociedad no es invulnerable; muestra que su ruptura, aun si es pequeña y cotidiana, causa conmoción, y además deja ver cómo todo esto no es un producto de consciencias racionales. Los rituales funerarios son maneras en que la sociedad se fortalece a sí misma después del embate de la muerte, pero los sujetos no tienen que estar concientes de ello para que el ritual funcione - por ejemplo, las personas se sienten mejor al llorar su pérdida en rituales mortuorios (Mandelbaum 1965), pero no porque estén plenamente conscientes de todos los mecanismos sociológicos y antropológicos que estos implican-. Igualmente, la creencia en la vida después de la muerte reduce la ansiedad respecto a esta (Rasmussen y Johnson, 1994), pero difícilmente se lograría este efecto si alguien intentara creer en el más allá con la intención consciente y razonada de manejar mejor su miedo a morir.

Entonces, para Durkheim, lo social es algo que conviene al individuo, pero es vulnerable y su ruptura es algo que causa reacciones pasionales y aversión en los sujetos. Además, todo esto sucede sin que las personas estén plenamente conscientes de sus intereses, sus riesgos y los mecanismos

\section{6}


que las protegen. La demanda moral aquí analizada parece compartir estos rasgos.

En las entrevistas se encontraron sujetos deseando que sus gobernantes fueran personas de moral intachable, aunque no resultaron capaces de explicar por qué; lo primero resulta lógico si tomamos en cuenta que los funcionarios son muy visibles y, aún peor, son electos. En la medida en que la sociedad reposa sobre una serie de axiomas y valores morales, y estos son vulnerables, la ruptura de estos principios genera animadversión en las personas, lo que es particularmente relevante cuando esta ruptura es visible, cuando es pública.

Uno de los informantes señaló que, al igual que los políticos, los sujetos que participan en las industrias del espectáculo son figuras públicas, y que en ambos casos el público parece muy interesado en sus vidas privadas. Aunque este símil no funcionara como un argumento común en otras entrevistas, da cuenta de cómo el simple hecho de que los políticos sean figuras visibles los hace objeto de escrutinio moral para los ciudadanos. También hay que recordar que los informantes deseaban que en principio todos fueran buenos, pero depositaban la demanda moral sobre aquellas figuras más visibles: párrocos, profesores, políticos, etc.

Entonces, la benignidad de lo social y su fragilidad parecen explicar la reacción visceral y el rechazo que provoca lo inmoral: ahí donde el mal aparezca, debe ser condenado, especialmente si es muy visible. En la medida en que los políticos son figuras públicas, son muy susceptibles al escrutinio y la censura moral, pero, contrario a los artistas, por ejemplo, para la sociedad tienen otra característica que los hace aun más relevantes: son votados. Las personas rechazan aquello que va en contra de sus valores, y si ser indiferente a una violación moral ya sería algo inadecuado, dar un voto por el violentador implicaría estar en el otro extremo del espectro y legitimar el mal; votar por un político 
malvado implica no sólo no condenar el mal, sino apoyarlo, lo que sería mucho peor a ojos de la sociedad analizada.

Esta relevancia moral de los políticos se refleja en lo antes dicho sobre la corrupción. Las personas no parecen rechazarla por una razón pragmática: no están molestas porque represente una pérdida significativa de dinero, sino porque está mal en sí misma y debe ser condenada. Igualmente, esto se refleja en las respuestas a la pregunta sobre si se aceptaría un gobernante eficaz pero malvado: las personas se incomodaron con el cuestionamiento (trastabilleos en sus respuestas, incapacidad de articulación), pues lógicamente deseaban un gobernante que diera buenos resultados, pero aceptar esa propuesta implicaría que el mal se estaría mostrando públicamente sin recibir condena.

Por su parte, la consciencia juega aquí un rol ambiguo, pues según Durkheim las personas no tienen que estar del todo conscientes de la fragilidad de lo moral y de cómo sus reacciones son producto del riesgo de anomia, pero tampoco tienen que ser completamente ignorantes de este hecho.

Hay que recordar que los entrevistados tenían cierta creencia de que el gobernante debería ser un ejemplo positivo o negativo para la ciudadanía. Según esta hipótesis, si el regente fuera bueno, la gente seguiría su ejemplo y los ciudadanos serían mejores personas, mientras que, si fuera malo, las personas -particularmente los niños- seguirían su ejemplo y serían malos.

Esta hipótesis nativa ${ }^{3}$ no tiene muchas probabilidades de ser cierta, pues la moral colectiva no parece tan fácil de alterar. Se sabe, por ejemplo, que la cultura política de un país tarda mucho en cambiar y que no se volverá democrática sólo porque el presidente tenga valores democráticos. Igualmente, el aumento en la brutalidad de la guerra contra

3. Con el adjetivo nativa se intenta dar a entender que esta hipótesis no proviene de ningún artículo científico ni de la teoría sociológica o política, sino que tiene origen en los mismos entrevistados.

\section{8}


el crimen organizado en México parece más el efecto de una mala planeación que consecuencia de los valores morales del presidente en funciones. Difícilmente las virtudes personales de los gobernantes (aun si se hacen públicamente visibles) lograrán tener gran impacto social; presumir la generosidad personal de un mandatario podría mejorar su imagen, pero probablemente no disminuiría la pobreza tanto como lo haría una política pública bien planificada y aplicada.

Aun si la hipótesis nativa resultara falsa, es una hipótesis razonable y muestra cómo los sujetos no son idiotas culturales (Garfinkel, 1967) que irreflexivamente siguen pautas sociales: las personas tienen consciencia, aunque es limitada. Esto recuerda el tema de la muerte.

Antropológicamente, sabemos que aquello que pertenece simultáneamente a dos categorías disyuntivas causa incomodidad (Douglas, 1973). Así, un recién fallecido todavía no es un antepasado, pues sigue teniendo asuntos en este mundo, pero tampoco es un ser vivo; es en esa incómoda zona gris entre la vida y la muerte donde el ritual mortuorio, entre otras cosas, cumple la función de transformar a un vivo en un ancestro benefactor (Hertz, 1960).

Probablemente, los actores en un funeral no están completamente conscientes de todo esto, pero sí lo notan, es decir, saben que el alma viaja a otro lugar y que los ritos le ayudan a llegar en paz a ese más allá. En la demanda moral mexicana respecto a los políticos, como en la visión durkhemiana de la muerte, los actores tienen noción de lo que hacen, pero no son sujetos plenamente conscientes ni siguen objetivos que maximicen su ganancia.

La moral quizá no es un fenómeno consciente, pero es importante y a la vez vulnerable, por lo que ninguna ruptura de ella deberá pasar inadvertida, menos aún si es pública. La teoría durkhemiana ayudó a comprender este fenómeno que las entrevistas presentaron difusamente. Surge ahora el tema de su dimensión: ¿cuán común es la demanda moral? 
¿Es intensa? ¿Es un fenómeno generalizado o exclusivo de una población reducida?

\section{Demanda moral cuantitativamente}

Casi cincuenta entrevistas realizadas en dos ciudades mexicanas fueron suficientes para clarificar conceptualmente el problema de investigación, pero difícilmente dan una idea de qué tan diseminada está la postura de los ciudadanos respecto a la demanda moral hacia sus gobernantes. Por ello, los hallazgos aquí presentados se trasformaron en reactivos de una encuesta que se aplicó a seiscientas noventa personas de varias ciudades y que permite tener no sólo una idea conceptual y teóricamente clara del fenómeno, sino también alguna impresión de su dimensión.

Evidentemente, lo más sencillo en términos metodológicos habría sido utilizar alguna de las encuestas grandes con representatividad nacional, como el Latinobarómetro o el informe país sobre la calidad de la democracia. Sin embargo, dichas encuestas están diseñadas para captar elementos de teorías más consolidadas, por lo que no tienen reactivos adecuados sobre la demanda moral. Debido a esto, fue necesario elaborar una encuesta propia, misma que por limitaciones de recursos para su aplicación no tendría representatividad nacional. En un intento por maximizar el número de encuestas, se decidió hacer el levantamiento en universidades públicas, cuya población es muy accesible.

Cabe mencionar que al elegir los lugares de aplicación, y para evitar sesgos, se evitaron las facultades de ciencias políticas y sociales, aunque obviamente se generó un sesgo por educación y edad. Para tener representatividad federal, se encuestó en las ciudades de Querétaro, Monterrey, Guadalajara, Ciudad de México, Puebla y Villahermosa. Las encuestas se aplicaron entre el 23 de abril y el 24 de mayo de 2018, fechas elegidas porque se acercaban a la elección

\section{0}


presidencial de 2018, aunque no lo suficiente como para que coincidieran con el periodo vacacional universitario (que en algunos casos inicia en junio). La muestra tiene un número similar de casos de cada ciudad: $51.9 \%$ de hombres, con edad promedio de 21.4 años y desviación estándar de 3.5.

El cuestionario incluía los siguientes reactivos con opción de respuesta:

- Creo que un presidente debe ser una buena persona independientemente de sus funciones legales/formales.

- Pienso que un presidente debe unir y guiar a la nación.

- Es posible ser buen presidente y mala persona a la vez.

También se incluyeron dos preguntas contiguas:

- Al evaluar candidatos, lo que más me interesa es su formación académica y experiencia profesional.

- $\mathrm{Al}$ evaluar candidatos, lo que más me interesa son sus valores morales, liderazgo y calidad como persona.

Finalmente, se hizo el ejercicio de indagar en qué medida la demanda moral se extendía a otros oficios, para lo cual se incluyeron las siguientes preguntas:

- Al elegir presidente, considero su calidad como persona además de sus capacidades como administrador y servidor público.

- Si pudiera elegir a mis profesores, lo haría considerando su calidad moral además de sus capacidades docentes.

- Si eligiera qué técnico arreglara mi computadora, me interesaría que fuera una buena persona, no sólo la calidad de su servicio.

- Me incomodaría ver una película si sé que su protagonista es una mala persona en su vida privada.

En todos los casos, se dieron cuatro opciones de respuesta: acuerdo total, poco acuerdo, poco desacuerdo y desacuerdo total. 
Sobre los primeros reactivos, se encontró que la demanda moral parece ser intensa (Figura 2).

Figura 2. Descripción de reactivos sobre opiniones morales

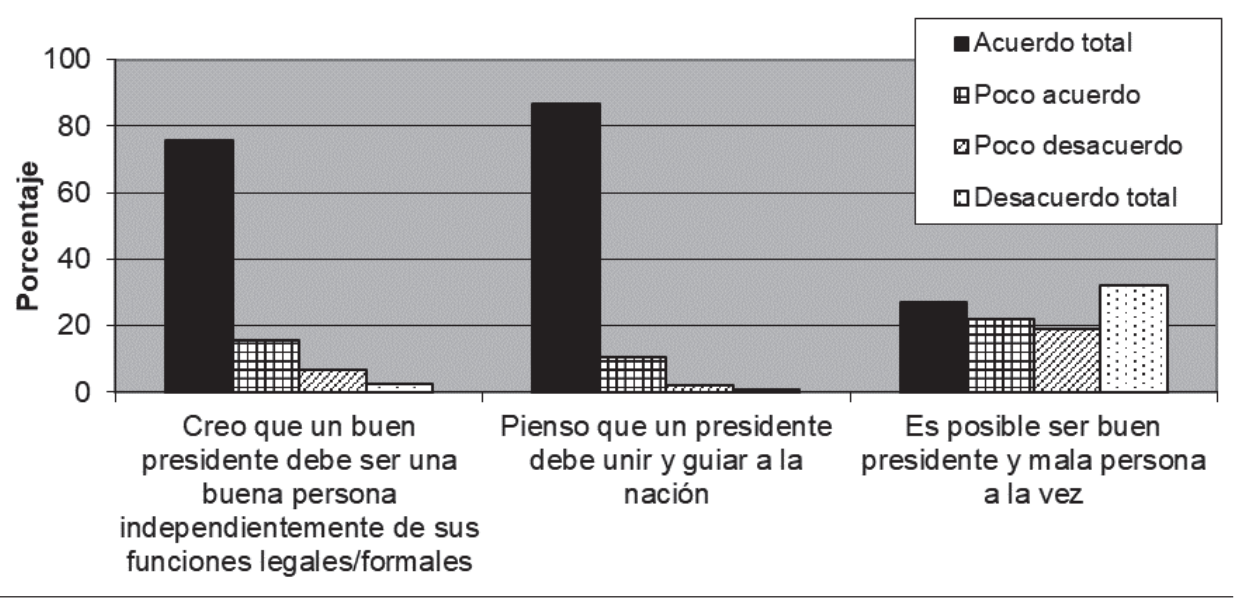

Fuente: elaboración propia con base en encuesta.

Como ya se había adelantado, las personas tienen muy claro que el presidente debe tener virtudes morales y que debe unir y guiar a la nación (85.9\%). El 76.2\% de los encuestados mostró el máximo acuerdo con la idea de que el presidente debe ser buena persona independientemente de sus funciones legales. Cabe señalar que no se encontraron diferencias muy notorias ni estadísticamente significativas en función de la ciudad analizada: todas las ciudades parecen tener opiniones similares.

El último reactivo de la Figura 2 es más ambiguo, pues como se mencionó en las entrevistas, algunas personas creen que no es posible que un político pueda ser un funcionario eficiente si no es una buena persona. No es una postura que todos los encuestados compartan, y esto habla de las complejas relaciones entre el juicio pragmático y el moral, asunto que se explorará en las conclusiones. 
Para entender más la relación entre la demanda moral y la pragmática, se preguntó cuál era la más importante (Figura 3).

Figura 3. Importancia relativa de cada factor

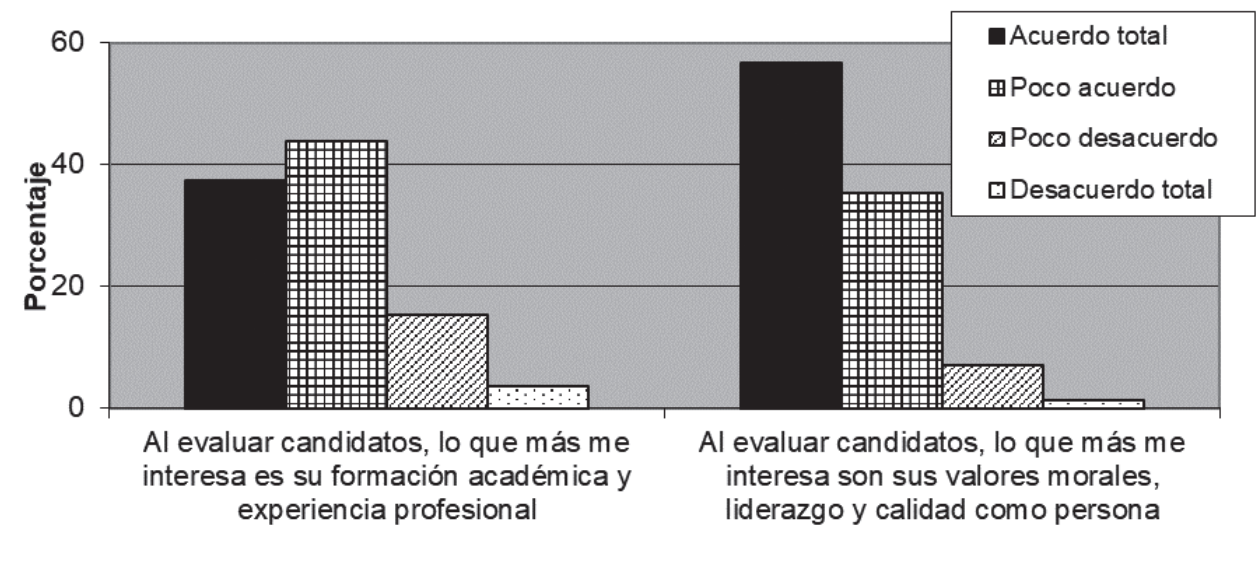

Fuente: elaboración propia con base en encuesta.

Nótese que ambas preguntas investigaban si el factor en cuestión era lo que más interesaba. Las personas dejaron clara la relevancia de lo moral, pero en principio deberían haber seleccionado sólo un elemento como el más importante, y el $28.8 \%$ de los encuestados respondió usando el máximo acuerdo en ambos reactivos. Podría pensarse que esto es un error del cuestionario, pero las preguntas eran contiguas y claras, por lo que parece más probable que el juicio ciudadano mezcle estos factores de maneras aún desconocidas, lo que también se revisará en las conclusiones.

Finalmente, con relación a la demanda moral hacia diversos oficios, se encontró que algunos de ellos son más propensos a este tipo de expectativas, y destacan aquellos con cierta verticalidad y visibilidad, como es el caso de políticos y profesores (Figura 4). 
Figura 4. Expectativa moral sobre diversos oficios

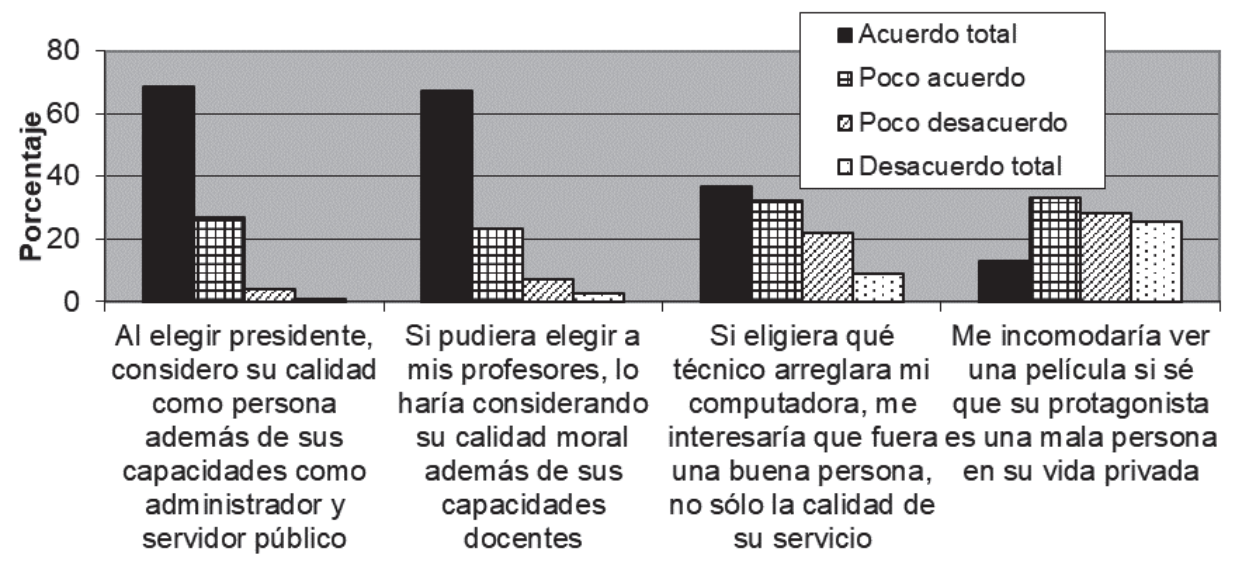

Fuente: elaboración propia con base en encuesta.

La expectativa moral parece recaer en el presidente más que en cualquier otra figura, pero es muy similar a la que se tiene hacia un profesor y contraria a la que se tendría, por ejemplo, hacia un técnico en computación, cuyas virtudes morales parecen importar poco; respecto al actor en una película, el resultado es difícil de interpretar, pues la escritura del reactivo fue cambiada ante la inexistencia de un patrón de coincidencia en su redacción, lo que podría haber afectado el ejercicio, aunque por otro lado esto también podría ser un indicio de que la expectativa moral depende menos de cuán visible es una figura y más de cuánto liderazgo se espera de ella.

Ahora bien, el cuestionario también incluyó una pregunta sobre cuánto dinero público (porcentaje) se creía que se perdía en corrupción, un cálculo que suele estar ubicado por debajo del 10\% (Figura 5). 


\section{Figura 5. Estimación ciudadana del porcentaje} de dinero público perdido por corrupción

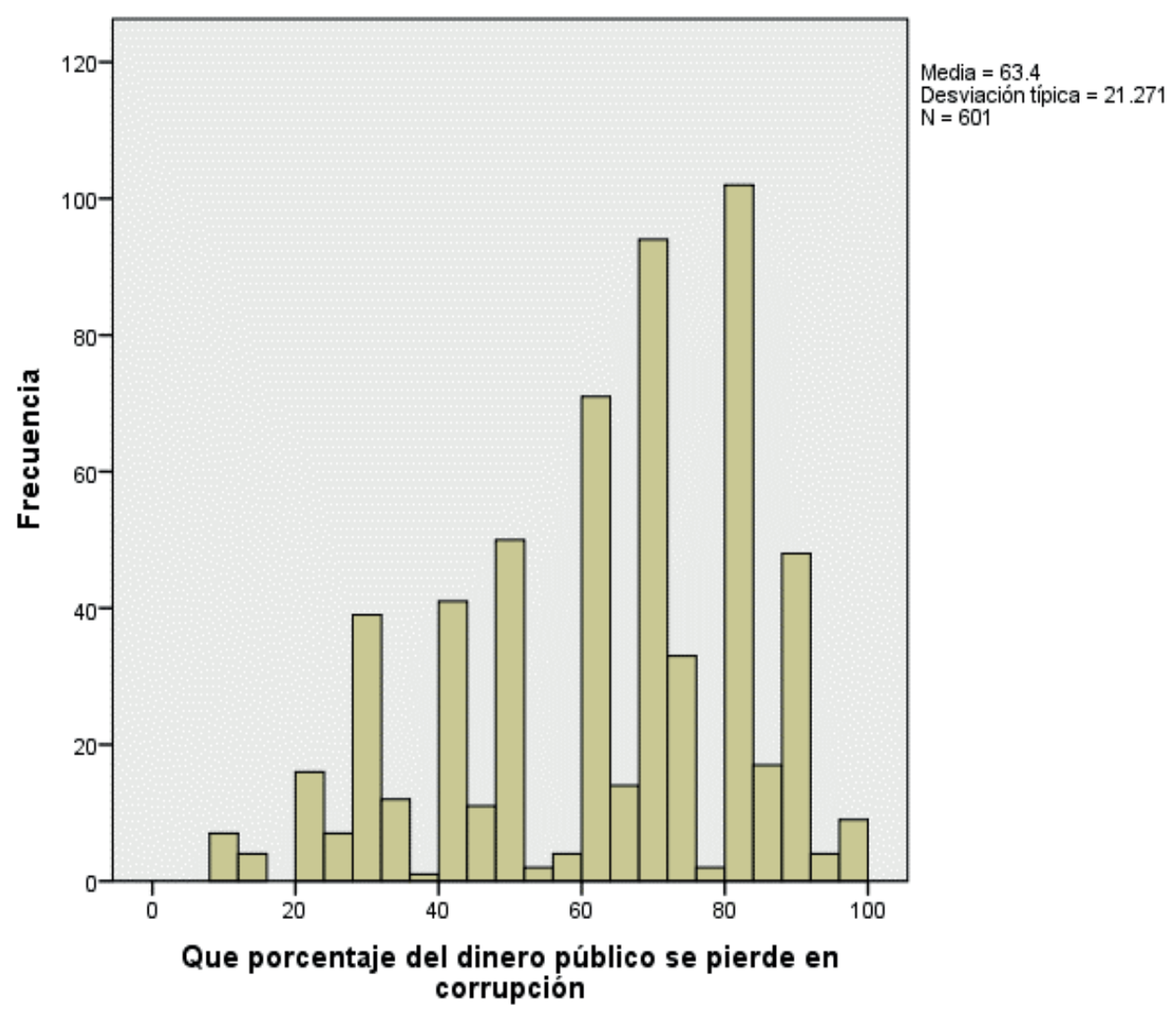

Fuente: elaboración propia con base en encuesta.

Con un promedio de $63.4 \%$ y desviación de 21.2 , es claro que los ciudadanos sobreestiman el tema de la corrupción por mucho, lo que es interesante, pues al ser un tema tan relevante y discutido se esperaría que la población supiera más sobre sus dimensiones.

Vale la pena recordar que estos hallazgos provienen de una muestra de estudiantes de licenciatura, por lo que no tienen representatividad nacional. No se puede saber qué habría resultado de una encuesta que sí contara con dicha representatividad, pero es razonable pensar que los jóvenes de licenciatura se encuentran entre la población 
más educada y con tendencias de pensamiento racional, lo que los hace a su vez menos propensos a juicios morales y más sensibles a temas pragmáticos. Si esto fuera cierto, la demanda moral que parece fuerte en estudiantes de licenciatura se esperaría aún más intensa en otras poblaciones.

\section{Conclusiones}

Después de la evidencia y reflexión aquí presentada, parece claro que los mexicanos no sólo juzgan a los políticos con base en el desempeño que han mostrado o parece que tendrán, sino que también depositan expectativas morales sobre ellos. Después de todo, la violación de lo moral causa animadversión, particularmente cuando es pública, y los políticos son no sólo públicos, sino electos. Además, esto no parece un fenómeno aislado ni exclusivo de un grupo específico, sino que la demanda moral pareciera ser intensa y generalizada en la población mexicana.

De inicio, es destacable que las teorías políticas más consolidadas no resultaron de ayuda en la comprensión del fenómeno analizado, pero sí la teoría sociológica clásica. Evidentemente, la demanda moral se relaciona con casi toda gran teoría política, pero sólo de forma tangencial y no al grado de que esta última sea de ayuda para clarificar el discurso de los entrevistados.

Durkheim sugiere que los valores sociales son positivos para el individuo, que su ruptura provoca una reacción visceral de aversión y que los actores tienen una consciencia limitada de este fenómeno, premisas todas que parecen coincidir con la actitud de los informantes de este estudio y aclarar algunas de sus incertidumbres y contradicciones.

El uso de teoría sociológica en un asunto político implica un cruce de disciplinas que podría abrir la puerta a muchos otros estudios interesantes. Por ejemplo, después de Durkheim muchos avanzaron su línea teórica, por lo que quizá 
haya elementos en los trabajos de Marcel Mauss o Levi Strauss que ayuden a entender mejor el aspecto de los juicios morales en la política, o incluso podría ser productivo recurrir a figuras menos cercanas a Durkheim para ello, como Radcliffe Brown, Parsons o Merton. El elemento moral de la política podría ser el terreno en que politólogos, sociólogos y antropólogos coincidan, lo que a su vez podría ayudar a comprender mejor la conducta política.

Por más innovadores e interesantes que puedan parecer estos hallazgos y futuras líneas de investigación, es claro que este trabajo tiene un alcance muy limitado y necesita consolidar muchas cosas. En primer lugar, es obvio que se necesita una encuesta de representatividad nacional, no sólo para confirmar la aparente intensidad del fenómeno en población abierta, sino también para tener información básica sobre él; la demanda moral podría estar correlacionada con la edad, ingreso, educación, geografía, religión, cultura política, postura ideológica (derecha-izquierda), identificación partidista, abstencionismo y otras variables.

También, es indispensable que se aclare el asunto de la demanda moral y la pragmática, pues no es claro si estos deseos son independientes o se vinculan, y, en el último caso, cómo es su relación. La población no parece muy capaz de juzgar objetivamente la economía ni la seguridad, y estos elementos no parecen explicar su opinión de los políticos (Gutiérrez, 2018); además, las personas fallan al intentar estimar la dimensión de la corrupción. No obstante, durante las entrevistas las personas hablaban de economía, de seguridad y de corrupción, y llegaban incluso a señalar que la situación nacional de estos elementos determinaba sus juicios.

Por otra parte, muchas personas decían que lo que más les interesaba era lo pragmático, y también decían que lo que más les interesaba era lo moral. ¿Cómo es que ambos elementos podrían ser simultáneamente superlativos? 
Finalmente, y aunque no se desarrolló aquí por no ser el tema del estudio, la encuesta contenía preguntas sobre los candidatos presidenciales del 2018 y encontró que quienes tenían buenas evaluaciones sobre lo moral también tenían buenas evaluaciones sobre lo pragmático, coincidencia difícil de entender. Una posible explicación a esto es que la gente en realidad no reaccione a lo pragmático, sino que utilice los datos que encuentra para justificar sus reacciones morales menos racionales, lo que además coincide con algunos trabajos según los cuales primero se tiene una reacción emocional hacia lo elegido y luego se buscan argumentos empíricos y objetivos que justifican la primera reacción, pero no la determinan (Haidt, 2003; Lodge y Taber, 2005). Esta opción es interesante, pero no hay suficiente evidencia ni en este estudio ni en ninguno de los trabajos aquí citados como para darla por verdadera, lo que supone la necesidad de más investigación.

También hay que agregar que este trabajo no aclara cómo la persona hace su juicio moral, es decir, con lo aquí mostrado queda claro que los mexicanos evalúan la moral personal de los políticos, pero ¿cómo hacen para saber que un candidato tiene los valores morales que quieren?, eso considerando el hecho de que la población no convive con los políticos directamente. Esto sugiere el desarrollo de nuevas líneas de investigación en comunicación política, mismas que en algún momento podrían explicar qué determina que una persona sienta o no esta conexión moral.

Con todo lo aquí presentado y discutido, la demanda moral sobre los políticos ya es mucho más clara, pero quedan muchas interrogantes que deberán ser atendidas, varias de las cuales tienen gran potencial para ayudar a comprender el comportamiento político de los mexicanos. 
Almond, G., y Verba, S. (1963). The Civil Culture. Princeton: Bibliografía Sage.

Alonso, J. (1994). Partidos y cultura política. En J. Alonso (Ed.), Cultura política y educación cívica (pp. II5-I84). México: CIIH-UNAM.

Alonso, J. (20I0). El movimiento anulista en 2009 y la abstención. Espiral estudios sobre Estado y sociedad, I6(47), 9-46. doi https://doi.org//0.32870/eees.v I6i47.1452

Campbell,A., Converse, P., Miller,W.,y Stokes, D. (1960). The American Voter. Nueva York:Wiley.

Consulta Mitofsky (I0 de junio de 2019). AMLO, en el top 5 global de aceptación y segundo en América. El Economista. Recuperado de https://www.eleconomista.com.mx/politica/AMLO-en-el-top-5-global-de-aceptacion-y-segundoen-America-20 I 906 I0-0004.html

Cuna, E. (2006). Reflexiones sobre el desencanto democrático. El caso de los partidos políticos y los jóvenes en la Ciudad de México. Sociológica, 2 I (6I), 95-I33. Recuperado de http://www.sociologicamexico.azc.uam.mx/ index.php/Sociologica/article/view/259

Cuna, E. (20/2).Apoyo a la democracia en jóvenes estudiantes de la Ciudad de México. Estudio sobre el desencanto ciudadano juvenil con las instituciones de la democracia mexicana. Polis, 8(2), I07-I5I. Recuperado de https:// revistas-colaboracion.juridicas.unam.mx/index.php/ polis/article/view/I 7034

Douglas, M. (1973). Pureza y peligro. Madrid: Siglo XXI.

Durkheim, E. (2000). Las reglas del método sociológico. México: Ediciones Quinto Sol.

Durkheim, E. (200I). Las formas elementales de la vida religiosa. México: Ediciones Coyoacán.

Durkheim, E. (2002). La división del trabajo social. México: Colofón.

Elias, N. (2008). Sociología fundamental. México: Gedisa. 
Bibliografía García, J. (2004). El malestar de la democracia en México. México: Plaza y Valdez.

Garfinkel, H. (1967). Studies in ethnomethodology. Nueva Jersey: Prentice-Hall.

Guardado, J. (2009). La identidad partidista en México. Las dimensiones políticas de la competencia en las elecciones presidenciales de 2000 y 2006. Política y Gobierno, (I, temático), I 37- I 75. Recuperado de http://www.politicaygobierno.cide.edu/index.php/pyg/article/view/652

Gutiérrez, H. (2017). Buenos ciudadanos que no votan: mecanismos entre desencanto y abstención. Sociológica, 92(32), I4I-I73. Recuperado de http://www.sociologicamexico.azc.uam.mx/index.php/Sociologica/article/ view/ I 42

Gutiérrez, H. (20I8). La desaprobación del Gobierno mexicano. Más que ineficiencia. Espiral estudios sobre Estado y sociedad, 25(72), 83-I21. doi https://doi.org//0.32870/ espiral.v25i72.6384

Haidt,J. (2003). The Moral Emotions. En R.J. Davidson, K. R. Scherer, y H. H. Goldsmith (Eds.), Handbook of Affective Sciences (Pp. 852-870). Oxford: Oxford University Press. Hertz, R. (1960). Death and the right hand. Gran Bretaña:The University Press Aberdeen.

Lijphart, A. (1999). Patterns of democracy. New Haven:Yale University Press.

Lodge, M., y Taber, C. (2005). The Automaticity of Affect for Political Leaders, Groups, and Issues: An Experimental Test of the Hot Cognition Hypothesis. Political Psychology, 26(3), 455-482. doi https://doi.org/ I 0 . I I I /j. I 467$9221.2005 .00426 . x$

Mandelbaum, D. G. (1965). Social uses of funeral rites. En H. Fiefel (Ed.), The meaning of death (pp. 189-2I7). Nueva York: McGraw-Hill.

Mora, J., y Rodríguez, R. (2003). Las elecciones intermedias del 2003: entre el desencanto político y la crisis de

\section{0}


representación. El Cotidiano, (19), 55-65. Recuperado de Bibliografía http://www.elcotidianoenlinea.com.mx/pdf/I 2207.pdf Moreno, A. (1999). Ideología y voto: dimensiones de la competencia política en México en los noventa. Política y Gobierno, vI(I), 45-8I. Recuperado de http://www.politicaygobierno.cide.edu/index.php/pyg/article/view/480

Moreno, A. (2009). La decisión electoral. Votantes, partidos y democracia en México. México: Porrúa.

Moreno, A., y Méndez, P. (2007). La identificación partidista en las elecciones presidenciales de 2000 y 2006 en México. Política y Gobierno, XIV(I), 43-76. Recuperado de http://politicaygobierno.cide.edu/index.php/pyg/article/ viewFile/270// 80

Rasmussen, C., y Johnson, M. (1994). Spirituality and religiosity: Relative relationships to death anxiety. Omega, 29(4), 3|3-3।8. doi https://doi.org//0.2/90/DIM93W6J-FY33-G3HQ

Schedler, A., y Sarsfield, R. (2009). Demócratas iliberales. Configuraciones contradictorias de apoyo a la democracia en México. Espiral estudios sobre Estado y sociedad, I5(44), I 23-I59. Recuperado de http://espiral.cucsh.udg. $\mathrm{mx/index.php/EEES/article/view/} \mathrm{I} 387$

Skinner-Burchus, F. (1977). Ciencia y conducta humana. Barcelona: Fontanella.

Torcal, M. (2003). Political disaffection and democratization history in new democracies. En M.Torcal,y J. R. Montero (Eds.), Political disaffection in contemporary democracies: social capital, institutions and politics (Pp. I57-189). Londres: Rutledge.

Weber, M. (2008). Economía y sociedad. México: Fondo de Cultura Económica.

Zovatto, D. (2002). Valores, percepciones y actitudes hacia la democracia. Una visión comparada latinoamericana: 1996-2002. América Latina hoy, 32, 29-53. Recuperado 
de http:// revistas.usal.es/index.php/I I30-2887/article/ view/2387

Zovatto, D. (2006). La participación electoral en América Latina: tendencias y perspectivas. En Tribunal Electoral del Poder Judicial de la Federación (Comp.), Memoria del iv Congreso Internacional de Derecho Electoral. Cultura democrática: abstencionismo y participación (pp. 23-50). México: Tribunal Electoral del Poder Judicial de la Federación. 